\title{
FACTORS INFLUENCING WEB SITE RESIDENCE TIME \\ OF THE ORB WEAVING SPIDER, MICRATHENA GRACILIS.
}

\author{
By Margaret A. Hodge* \\ Department of Entomology, University of Georgia, \\ Athens, Georgia 30602
}

\section{INTRODUCTION}

The word "habitat" may be used with varying degrees of precision. When describing the finer details of where an animal lives, the term microhabitat is often used to distinguish this from the particular community or ecosystem. Examination of microhabitat selection involves determining the factors which influence preference for a certain site. Many factors have been shown to affect the length of time that spiders will spend at a particular web site. Physical settings providing protection against web destruction by wind or rain may be important (Eberhard 1971; Enders 1976; LeSar \& Unzicker 1978; Marson 1974). Prey abundance, as well as factors relating to prey detection and capture sucess, are also important in microhabitat selection (Riechert \& Tracy 1975; Riechert 1976). Because food resources have been demonstrated to have a large impact on individual fitness in several spider species (Deevey 1949; Turnbull 1965; Miyashita 1969; Hagstrum 1970; Kessler 1973; Greenstone 1978; Kajak 1978; Morse \& Fritz 1982; Wise 1975) web site selection should be expected to be strongly linked to food supply. Studies which have examined the dynamics of prey availability have implicated web site relocation as a proximate mechanism for food supply enhancement (Turnbull 1964; Riechert 1978; Olive 1982; Janetos 1982).

Micrathena gracilis (Walckenaer) is an orb weaving spider common to deciduous forests throughout northeastern North America. These spiders characteristically build webs spanning large open areas between vegetation $(90-250 \mathrm{~cm})$. Certain individuals may

*Present Address: Department of Biological Sciences, M.L.\#6, University of Cincinnati, Cincinnati, Ohio 45221

Manuscript received by the editor July 24, 1987. 
occupy a web site for many days, and even weeks, whereas others relocate frequently. Since web site relocation requires a greater energy expenditure than does remaining at a site, the decision to leave may be related to the quality of the web site. This study used residence time at a particular web site as an indicator of microhabitat suitability and examined the relative contributions of feeding rates, web destruction, and sun-exposure (heat stress) to the tendency of a spider to remain at a web site.

\section{Methods}

This study was conducted in an approximately one-acre area of deciduous forest on the University of Georgia campus, Athens, Georgia (Clarke County). A thick understory of Rubus sp. (blackberry) and Rhus radicans (poison-ivy) and a canopy of Quercus alba constituted the major plant species of the study site.

One 12 July 1984, $25 \mathrm{M}$. gracilis were collected from the study site and from the University of Georgia Botanical Gardens. Only penultimate and mature females were collected. Spiders were marked with fast-drying enamel paint, using the positioned dots technique (Walker \& Wineriter 1980). Ten spines on the abdomen of M. gracilis made convenient locations for different combinations of paint marks, giving each spider a unique identity. This paint mark identity was assigned a number to simplify data collection. Blue, green, white and black paint were used on the rationale that these colors would have the least effect in making the spider more conspicuous to vertebrate predators (though Rypstra (1984) has found that such paint marks may have very little effect on predation rates). Spiders were retained for 24 hours to assure that they would survive the marking procedure (which involved no anesthesia).

Spiders were released at random locations (using the wandering quadrant technique of Catana (1955)) at $1800 \mathrm{hrs}$ on $13 \mathrm{July}$, and allowed 6 days to establish a web site. Observations were initiated on 20 July. The position of each spider was marked with a flag bearing its number identity, placed in the ground below the web. Unmarked spiders were marked in the field as they were discovered. Each day the distance (if any) moved by each spider was measured with a tape measure and recorded. Each web was checked hourly from 1000 hours until 1700-1900 hours. The following information was recorded at each hourly check: if the spider was feeding, was in 
direct sunlight and/or assuming a thermoregulatory position (Robinson \& Robinson 1979), and the condition of the web (extent of damage, if any). These observations were made from approximately $1 \mathrm{~m}$ from the web, to avoid disturbing the spider. Thus it was not possible to measure prey lengths. However, if a spider captured a large prey item it was likely to feed for 2-3 hours (personal observation). This was recorded as 2-3 observations of feeding in the hourly censuses. Therefore, the feeding rate, equal to the number of feeding observations, is an estimate of the prey consumed by a spider at a particular web site. Other information, such as molting, mating activity, predation, and intra- or interspecific interactions were also recorded. The study was terminated on 11 August, 1984.

\section{RESULTS}

The average web site residence time was 6.7 days (S.D. $=5.29$ days). Residence times were compared to values expected from a negative exponential distribution, which indicates random processes in time (Bailey 1964; Ross 1970). The distribution of observed residence times was significantly different from that expected by a random process $\left(\chi^{2}=1889 ; p \ll 0.001\right.$; Fig. 1$)$.

A total of 2131 web observations were made by checking spiders at hourly intervals. Of this total, there were few observations of sun-exposure or thermoregulation, and of these, few were followed by web site relocation (Table 1). A much greater percentage of the total number of relocations occurred following web destruction and/or were preceded by days of scarce prey (Table 1). There were 36 web site relocations during the study, and 34 of these were preceded by a day of either zero or one feeding observation, and/or web destruction by wind or rain. Only two relocations were not associated with either of these variables. Eighteen of the web relocations were preceded by web destruction. Thirteen of these 18 were simultaneously associated with low feeding rates. Sixteen relocations were associated with low feeding rates alone. A Chi-square test for independence led to acceptance of the null hypothesis that web relocation was not differentially influenced by either low prey levels (0-1 prey observations/day) or web destruction, or even by a combination of the two (Table $1 ; \chi^{2}=2.16, p>0.50$ ), i.e., both factors seemed to have a similar contribution to the decision to move. A feeding rate, equal to the number of feeding observations divided by 


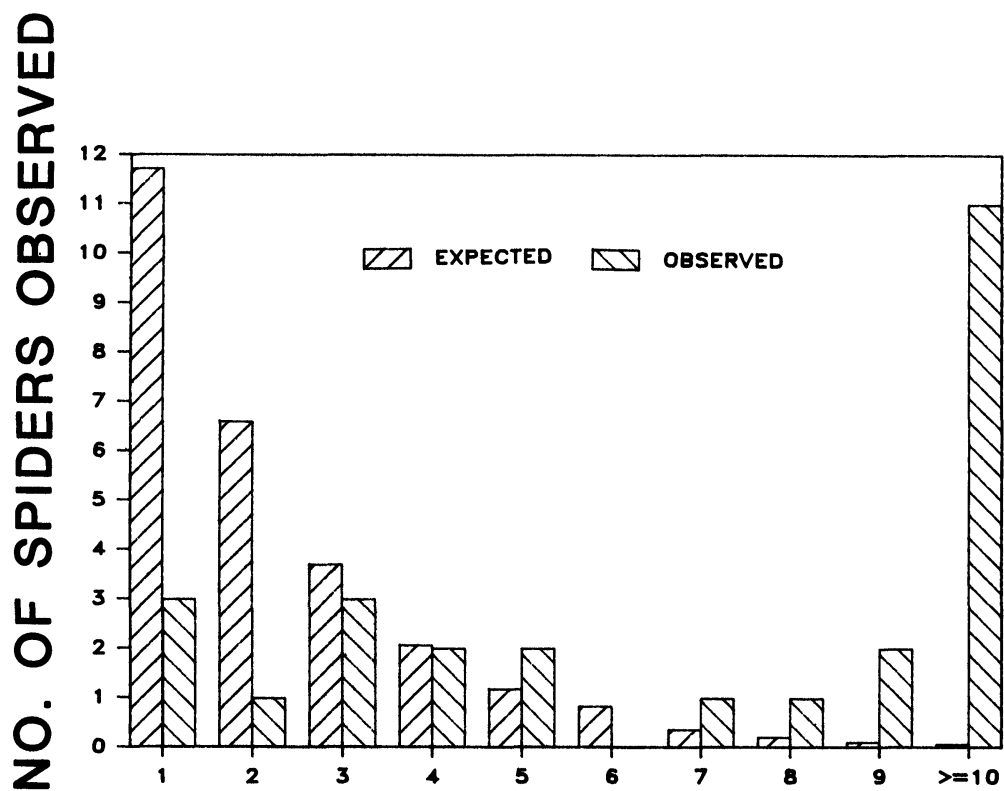

\section{DAYS AT WEB SITE}

Figure 1. Distribution of observed residence times compared to that expected by a random process (significantly different, $\mathrm{p}<0.001$ ).

the residence time (days) at the site, was calculated for each web site occupied. There was a significant difference $(t=2.55 ; \mathrm{p}<0.05)$ between the feeding rates of spiders staying $1-5$ days $\left(\bar{x}=0.89 ; \sigma^{2}=\right.$ $0.59)$ versus those staying for 6 days or longer at a site $\left(\overline{\mathrm{x}}=1.5 ; \sigma^{2}=\right.$ $.53)$.

\section{Discussion}

Since the web is the only means an orb weaving spider has of encountering prey, web site selection has important consequences with respect to the spider's fitness. Physiological studies have shown that finding a web site and building a web are energetically costly activities for orb weaving spiders (Witt et al., 1968; Peakall \& Witt 1976; Prestwich 1977). If behaviors associated with web site choice and tenacity have been selected for, then these choices should be 
Table 1. Number of spiders relocating after exposure to various environmental factors.

\begin{tabular}{lccc}
\hline $\begin{array}{l}\text { Environmental } \\
\text { Factor }\end{array}$ & $\begin{array}{c}\text { Spider } \\
\text { Relocation }\end{array}$ & $\begin{array}{c}\text { \% of total } \\
\text { relocations }\end{array}$ & $\begin{array}{c}\text { No spider } \\
\text { relocation }\end{array}$ \\
\hline $\begin{array}{l}\text { Exposure to } \\
\text { direct sunlight }\end{array}$ & 3 & $8 \%$ & 45 \\
$\begin{array}{l}\text { Thermoregulatory } \\
\text { posture }\end{array}$ & 1 & $3 \%$ & 3 \\
$\begin{array}{l}\text { Courtship attempts } \\
\begin{array}{l}\text { Web destruction } \\
\text { alone }\end{array}\end{array}$ & 3 & $8 \%$ & 15 \\
$\begin{array}{l}\text { Low prey levels } \\
\text { alone }\end{array}$ & 5 & $15 \%$ & 39 \\
$\begin{array}{l}\text { Both low prey and } \\
\text { web destruction* }\end{array}$ & 16 & $47 \%$ & 63 \\
\hline
\end{tabular}

*Chi-square test for independence indicates no differential influence of web destruction alone, low prey levels alone, or a combination of these factors on relocation; $\chi^{2}=2.16, \mathrm{p}>0.50$.

significantly correlated with the animal's energy gain, and therefore its fitness. Though a correlation between energy gain and fitness has not been shown for $M$. gracilis, it has been for many spider species (Deevey 1949; Turnbull 1962, 1965; Miyashita 1969; Hagstrum 1970; Kessler 1973; Greenstone 1978; Kajak 1967, 1978; Wise 1975, 1983). Morse \& Fritz (1982) found that female crab spiders gain $7 / 8$ of their biomass during the adult stage, which was the stage of most of the spiders observed in this study. Since biomass accumulation is crucial for egg production, it seems that web site residence time should be related to the energetic costs and benefits of moving versus staying. Factors such as web destruction (reduction of feeding time; cost of rebuilding) or low feeding rates may lead to a threshold hunger level which stimulates the spider to move.

The fact that 33 of 34 web relocations were preceeded by a day of low prey levels (0-1 feeding observations/day) and/or web destruction seems strong evidence that these factors are involved in the decision to move. However, most occurrences of low feeding rates and/or web destruction did not result in relocation (Table 1). The only conclusions that can be made from these data are that, although these two factors are almost always associated with web relocation, their occurrence alone is not enough to cause the spider 
to move. Some undetected environmental and/or physiological factors must contribute to the decision to relocate.

The two categories of residence times used in comparison of feeding rates were based on the average residence time of 6.7 days. Spiders staying at web sites for longer periods than six days had significantly higher feeding rates than those staying at web sites for five days or less. Olive (1982) has similarly shown that Argiope spp. moved more often when current feeding levels were decreased, and Vollrath (1985) observed that Nephila clavipes in poor environments changed sites more often than spiders in rich environments. Martyniuk (1983) found that filmy-dome spiders (Linyphiidae) which were moved to previously abandoned web sites of low prey availability and were provided with supplemental prey, remained at those sites.

Janetos (1982) has designated sheet-web weavers as "sit-and-wait" predators and orb weavers as "active" foragers. He assumed that orb webs could be put nearly anywhere, resulting in high variance in payoffs. Therefore, he predicted that orb weavers would do better by moving frequently among sites to find potential "hot spots." The assumption that orb webs can be put anywhere may not be correct. Several studies have shown that $M$. gracilis requires specific structural characteristics for web construction (Biere 1977; Hartsock 1983; Hodge 1985). Neither does M. gracilis follow Janetos's (1982) prediction of frequent movement among sites. Studies of $M$. gracilis and M. schreibersi (Perty) (Shelly 1984; Hodge 1985) have shown that these spiders often remain at web sites for 15 days or more. This contests the generalization that orb weavers are "active" foragers.

If spider web site relocations occur at random, then the expected distribution of intervals between relocations will follow a negative exponential distribution, which is a Poisson process (Bailey 1964; Ross 1970). If so, then the stimuli that induce a spider to leave a web site occur with a constant small probability in any short period of time. Such stimuli could be physical disturbance of the web due to climatic factors, or predation attempts (Janetos 1982). Comparison of the actual distribution of residence times with that expected from the random movement hypothesis indicates that $M$. gracilis does not move at random. A previous study of macrohabitat selection by $M$. gracilis found that spiders moved with a random pattern until they encountered a macrohabitat where environmental factors are ameliorated (Hodge 1988). This macrohabitat was a deciduous forest 
similar to the area in the present study. The distribution of residence times in these deciduous forest areas is almost identical, and both are significantly different from that predicted by the negative exponential. An interpretation of these distributions may be as follows. If each successive interval of nonperformance of a behavior depletes the animal's energy reserves, performance of the behavior (i.e., web site relocation) becomes more beneficial as the time elapsed since the last performance increases (Fagan \& Young 1978). This applies to $M$. gracilis in that if a spider at a certain web site experiences a reduction in prey capture due to web destruction and/or low feeding rates, then the time between relocations (time spent at that site) results in a certain depletion of the spider's energy reserves. This may culminate in some energy-related cue, perhaps a threshold hunger level, which stimulates the spider to perform the behavior of web site relocation.

\section{SUMMARY}

This study examined the factors influencing web site residence time of the orb weaving spider Micrathena gracilis. Residence time at a particular site was used as an indicator of microhabitat quality. When spider residence times were compared to a negative exponential distribution, the distribution of observed residence times was significantly different from that expected from a random movement hypothesis. The relative contributions of prey consumption, web destruction, and sun-exposure (heat stress) were monitored by hourly census checks of marked spiders over a 22 day period. Thirty-four of 36 web site relocations were preceded by a day of either zero or one feeding observation, and/or web destruction by wind or rain. There were few observations of sun-exposure accompanied by thermoregulatory posturing, and of these, few were followed by web site relocation. Web destruction and low prey levels are suggested as contributing to a threshold hunger level which stimulates spiders to seek new web sites.

\section{ACKNOWLEDGMENTS}

I would like to thank Drs. R. W. Matthews and J. O. Howell for providing the financial support and the opportunity to conduct this study. Drs. J. Arnold and G. Morrison provided statistical advice and Drs. G. W. Uetz and A. L. Rypstra offered valuable editorial 
comments. I am especially grateful for the support of J. Pettis and D. Willer during this study. This research was funded by the University of Georgia, Department of Entomology, Athens, Georgia, and the Georgia Experiment Station, Experiment, Georgia.

\section{REFERENCES}

BaIley, N. T. J. 1964. The elements of stochastic processes with applications to the natural sciences. J. W. Wiley \& Sons, Inc. New York, N.Y.

BIERE, J. M. 1977. Web orientation in the spider Micrathena gracilis (Araneae: Araneidae). M.S. Thesis. University of Cincinnati, Cincinnati, Ohio, USA.

Catana, A. J. 1955. The wandering quadrant: a new ecological method utilizing interspace measurements. Bull. Ecol. Soc. 36: 88.

DeEvey, G. B. 1949. The developmental history of Latrodectus mactans (Fabr.) at different rates of feeding. Am. Midl. Nat. 42: 189-210.

EBERHARD, W. G. 1971. The ecology of the web of Uloborus diversus (Araneae: Uloboridae). Oecologia 6: 328-342.

ENDERS, F. 1976. Effects of prey capture, web destruction and habitat physiognomy on web site tenacity of Argiope spiders (Araneidae). J. Arachnol. 3: 75-82.

FAGAN, R. M. AND Young, D. Y. 1978. Temporal patterns of behaviors: durations, intervals, latencies, and sequences. In: Colgan, P. W. (ed.), Quantitative Ethology. John Wiley \& Sons, New York, N.Y., pp. 79-114.

Greenstone, M. H. 1978. The numerical response to prey availability of Pardosa ramulosa (McCook) (Araneae: Lycosidae) and its relationship to the role of spiders in the balance of nature. Symp. Zool. Soc. Lond. 42: 183-193.

Hagstrum, D. W. 1970. Ecological energetics of the spider Tarentula kochii (Araneae: Lycosidae). Ann. Entomol. Soc. Am. 63: 1297-1304.

HaRTSOCK, S. P. 1983. The influence of web structure and web placement on prey capture in orb-weaving spiders. Master's Thesis, University of Cincinnati, Cincinnati, Ohio, USA.

Hodge, M. A. 1985. Macro- and microhabitat selection by the spiny orb weaving spider, Micrathena gracilis. Master's Thesis, University of Georgia, Athens, Georgia, USA.

1988. Macrohabitat selection by the orb weaving spider, Micrathena gracilis. Psyche, 94: 347-361.

JANETOS, A. C. 1982. Foraging tactics of two guilds of web-spinning spiders. Behav. Ecol. Sociobiol. 10: 19-27.

KaJAK, A. 1967. Productivity of some populations of web spiders. In: Petrusewicz, K. (ed.), Secondary productivity of terrestrial ecosystems. PWN, Warszawa-Krakow.

1978. Analysis of consumption by spiders under laboratory and field conditions. Ekol. pol. 26: 409-427.

KeEsLer, A. 1973. A comparative study of the production of eggs in eight Pardosa species in the field (Araneae, Lycosidae). Tijdschr. Entomol. 116: 23-41.

Kronk, A. W. AND Riechert, S. E. 1979. Parameters affecting the habitat choice of Lycosa santrita Chamberlin \& Ivie. J. Arachnol. 7: 155-166.

LeSAR, C. D. AND UnzICKer, J. D. 1978. Life history, habits and prey preferences of Tetragnatha laboriosa (Araneae: Tetragnathidae). Environ. Ent. 7: 879-884. 
MarSon, J. 1974. Some observations on the variation in the camouflage used by Cyclosa insulana (Costa), an Asiatic spider in its web. Proc. Zool. Soc. Lond. 11: 598-605.

Martyniuk, J. 1983. Habitat selection in Neriene radiata, the filmy dome spider (Araneae: Linyphiidae). Ph.D. Dissertation, State University of New York, Binghamton, N.Y., USA.

MiyashitA, K. 1969. Seasonal changes of population density and some characteristics of overwintering nymphs of Lycosa t-insignita Boes et Str. (Araneae: Lycosidae). Appl. Entomol. Zool. 4: 1-8.

MoRSE, D. H. AND Fritz, R. S. 1982. Experimental and observational studies of patch choice at different scales by the crab spider Misumena vatia. Ecology 63: 172-181.

Olive, C. W. 1982. Behavioral response of a sit-and-wait predator to spatial variation in foraging gain. Ecology 63: 1912-1920.

Peakall, D. B. AND WitT, P. N. 1979. The energy budget of an orb web-building spider. Comp. Biochem. Physiol. (A). 54: 187-190.

Prestwich, K. W. 1977. The energetics of web-building spiders. Comp. Biochem. Physiol. 57: 321-326.

Riechert, S. E. 1976. Web-site selection in the desert spider, Agelenopsis aperta (Gertsch). Oikos 27: 311-315.

1978. Games spiders play: behavioral variability in territorial disputes. Behav. Ecol. Sociobiol. 3: 135-162.

AND TRACY, C. R. 1975. Thermal balance and prey availability: bases for a model relating web-site characteristics to spider reproductive success. Ecology 56: $265-285$.

Robinson, M. H. AND RoBinson, B. 1979. Thermoregulation in orb-web spiders: new descriptions of thermoregulatory postures and experiments on the effects of posture and coloration. Zoo. J. Linn. Soc. 64: 87-102.

Ross, S. M. 1970. Applied probability models with optimization applications. Holden-Day, San Francisco.

Rypstra, A. L. 1984. A relative measure of predation on web-spiders in temperate and tropical forests. Oikos 43: 129-132.

Shelly, T. E. 1984. Prey selection by Micrathena schreibersi with notes on web site tenacity. Proc. Entomol. Soc. Wash. 86: 493-502.

Turnbull, A. L. 1962. Quantitative studies of the food of Linyphia triangularis (Clerck) (Araneae: Linyphiidae). Can. Entomol. 94: 1233-1249.

1964. The search for prey by a web-building spider Achaearanea tepidariorum (C. L. Koch) (Araneae, Theridiidae), Can. Entomol. 96: 568-579.

1965. Effects of prey abundance on the development of the spider Agelenopsis potteri (Blackwell) (Araneae: Agelenidae). Can. Entomol. 97: 141-147.

Vollrath, R. 1985. Web spider's dilemma: a risky move or site dependent growth. Oecologia 68: 69-72.

W ALKER, T. J. AND WINERITER, S. A. 1980. Marking techniques for recognizing individual insects. Fla. Entomol. 64: 18-29.

WiSE, D. H. 1975. Food limitation of the spider Linyphia marginata: experimental field studies. Ecology 56: 637-646.

1983. Competitive mechanisms in a food-limited species: relative importance of interference and exploitative interactions among labrinth spiders (Araneae: Araneidae). Oecologia 58: 1-9.

Witt, P. N., Reed, C. F., and Peakall, D. B. 1968. A spider's web: problems in regulatory biology. Springer Verlag, Inc. New York, N.Y. 

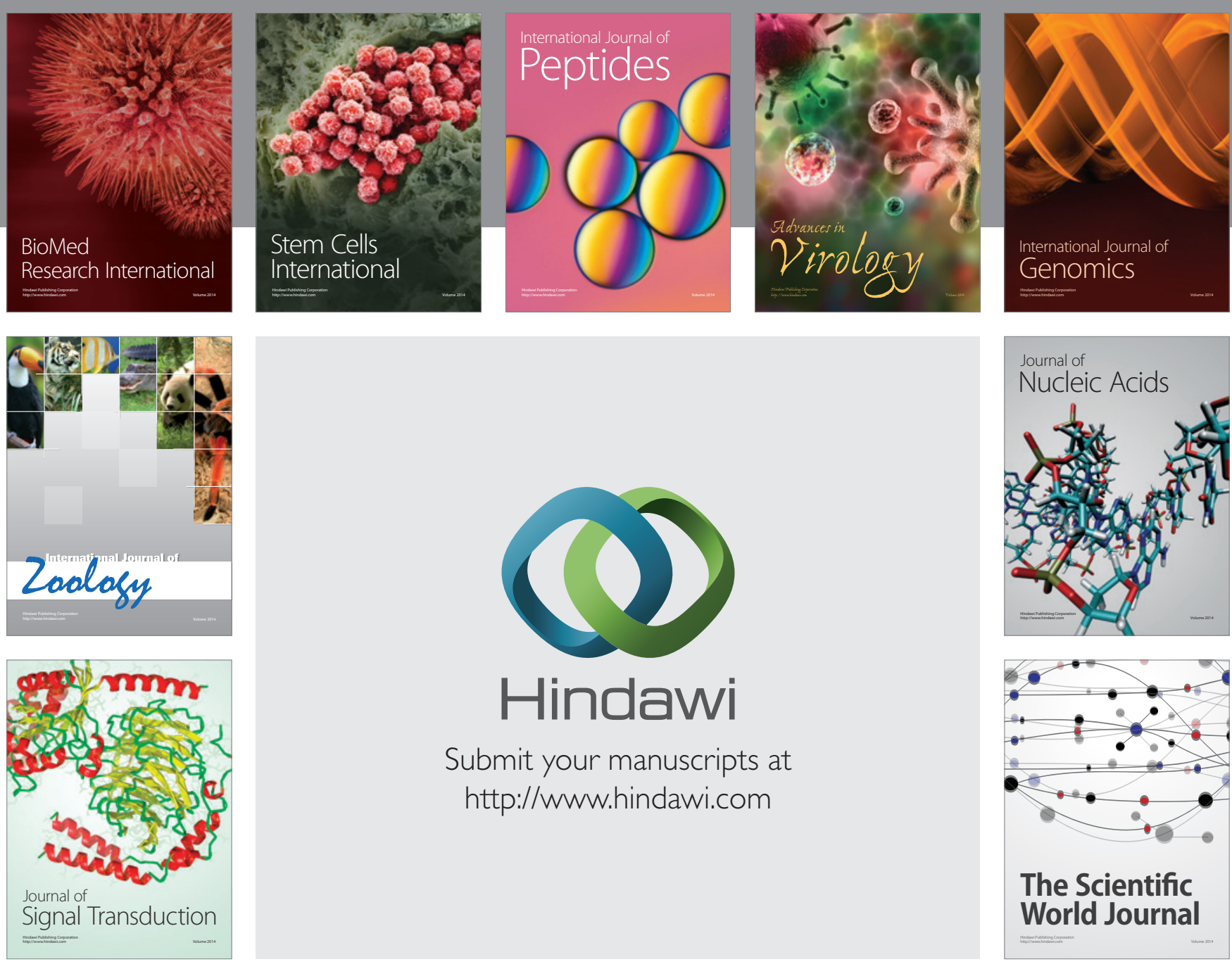

Submit your manuscripts at

http://www.hindawi.com
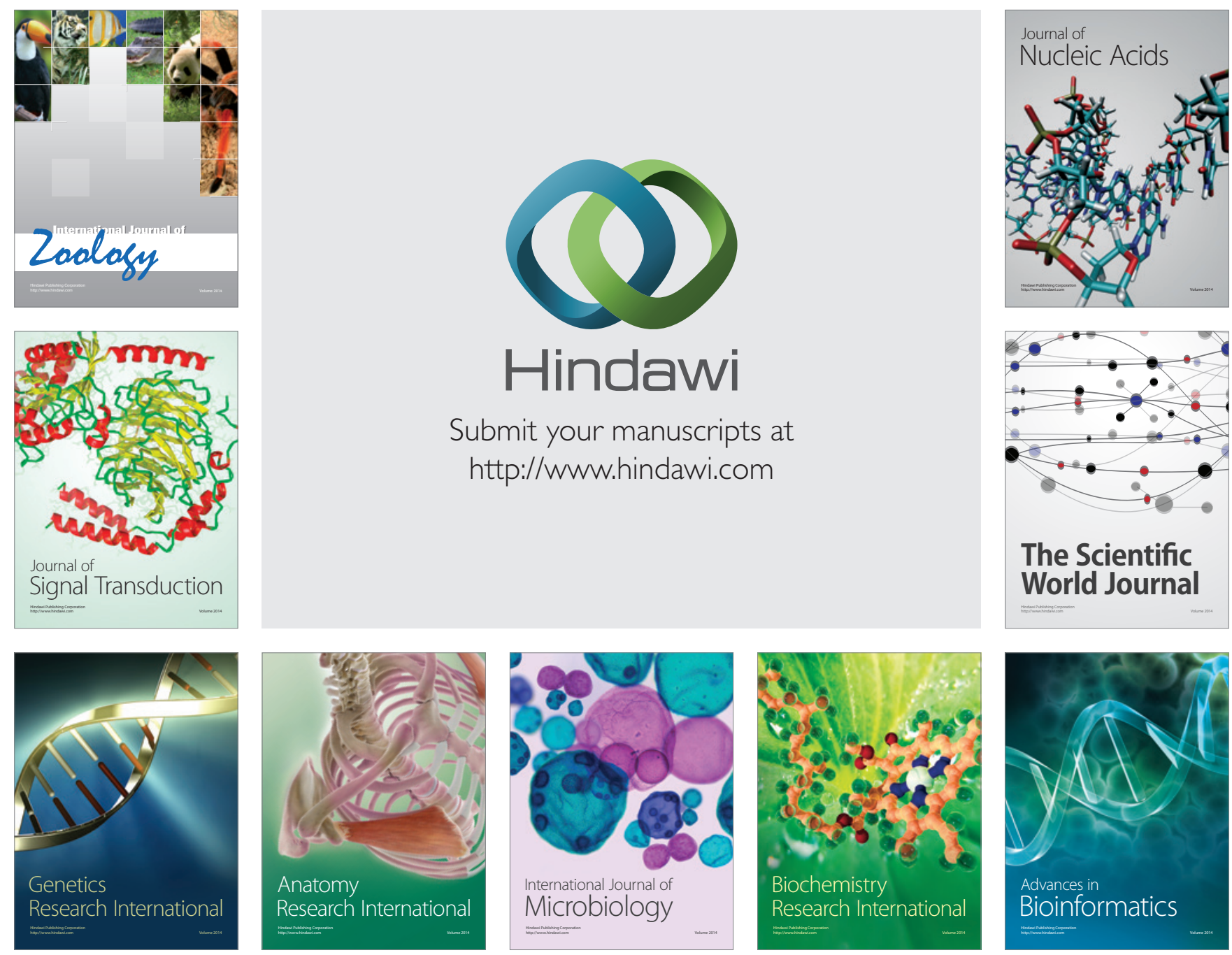

The Scientific World Journal
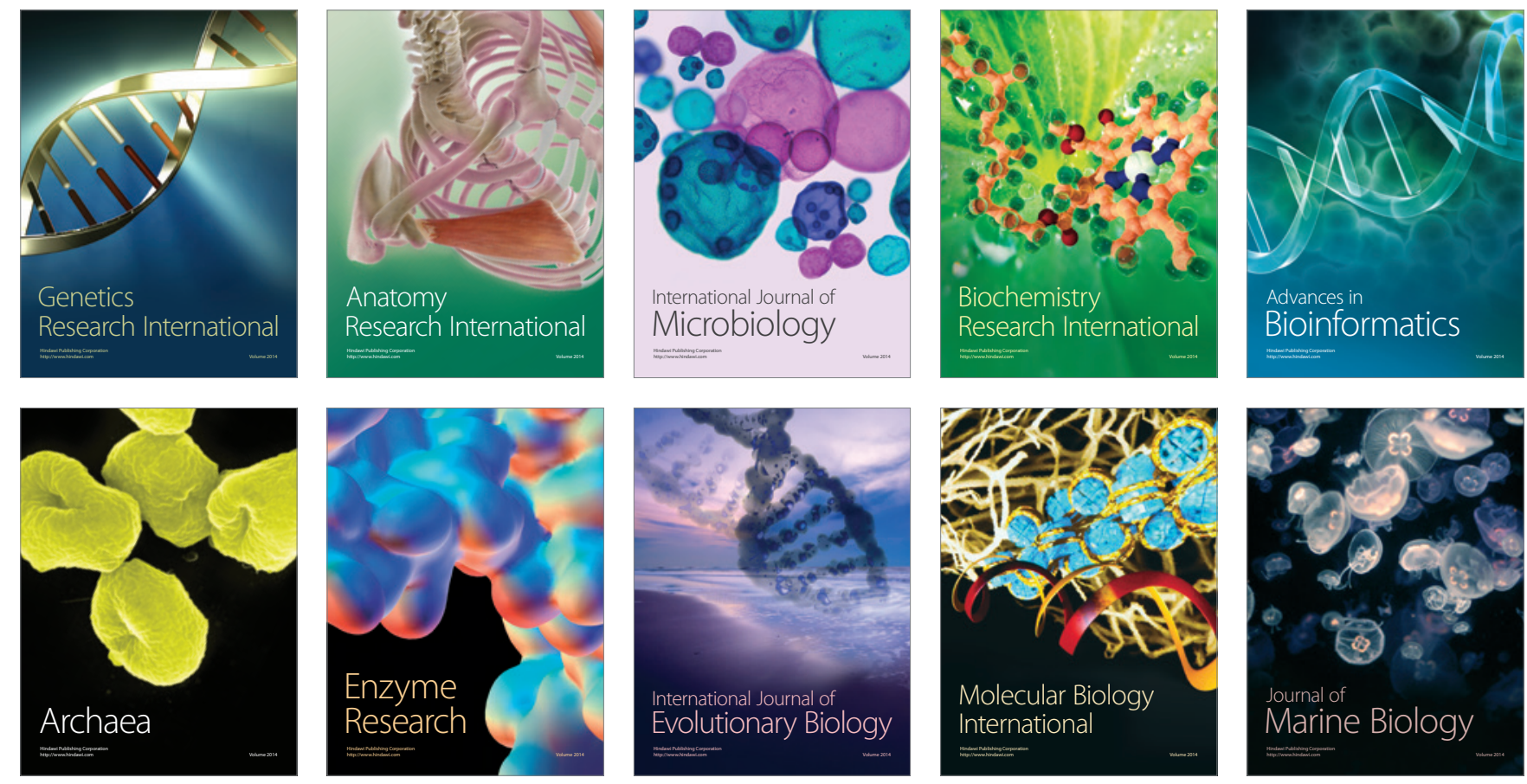